\title{
HUBUNGAN DUKUNGAN KELUARGA DENGAN KEPATUHAN DIIT RENDAH GARAM PADA PASIEN HIPERTENSI DI KAMPUNG MEKAR SARI KABUPATEN TANGERANG
}

\author{
Hera Hastuti ${ }^{1}$, Intan Adi Tyastuti ${ }^{2}$ \\ 1. Prodi S1 Keperawatan dan Ners Fakultas Ilmu Kesehatan, Universitas Muhammadiyah Tangerang \\ 2. Mahasiswa Prodi S1 Keperawatan \& Ners Fakultas Ilmu Kesehatan Universitas Muhammadiyah \\ Tangerang
}

\begin{abstract}
ABSTRAK
Hipertensi merupakan suatu keadaan ketika tekanan darah sistolik lebih dari $120 \mathrm{mmHg}$ dan tekanan darah diastolik lebih dari $80 \mathrm{mmHg}$. Kepatuhan diit rendah garam memerlukan waktu yang cukup lama sehingga dibutuhkan dukungan keluarga agar tercapainya kepatuhan diit rendah garam pada pasien Hipertensi. Penelitian ini bertujuan untuk mengidentifikasi hubungan antara dukungan keluarga terhadap kepatuhan diit rendah garam pada pasien Hipertensi di Kampung Mekar Sari Kabupaten Tangerang. Jenis penelitian ini adalah penelitian deskriptif analitik dengan pendekatan cross sectional. Sampel pada penelitian ini sejumlah 42 sampel. Data didapatkan dengan memberikan kuesioner kepada responden yang kemudian diolah dengan uji analisis Chisquare. Hasil penelitian didapatkan responden dengan Hipertensi 1 sebanyak 26 orang (61,9\%) dan Hipertensi 2 sebanyak 16 orang $(38,1 \%)$, keluarga yang memberikan dukungan keluarga secara baik terhadap responden Hipertensi sebanyak 27 orang $(64,3 \%)$ sedangkan keluarga yang tidak memberikan dukungan keluarga secara tidak baik terhadap responden Hipertensi sebanyak 15 orang $(35,7 \%)$ dengan uji analisis Chi-square didapatkan dukungan baik 64,3\% dan kepatuhan terhadap diit rendah garam 54,8\% dengan nilai $\mathrm{p}$-value $=0,002$. Kesimpulan dari penelitian ini yaitu dukungan keluarga pasien Hipertensi berhubungan dengan kepatuhan dalam menjalankan diit rendah garam pada pasien Hipertensi sehingga penting untuk meningkatkan kepatuhan pasien Hipertensi agar tercapainya program diit rendah garam pada pasien Hipertensi. Diharapkan keluarga selalu memberikan support dan perhatian terhadap kesembuhan pasien. Kesembuhan pasien ini harus ditunjang dengan partisipasi petugas kesehatan dalam meningkatkan pemahaman pasien terhadap diit rendah garam pada pasien hipertensi.
\end{abstract}

Kata Kunci: Dukungan Keluarga, Kepatuhan, Pasien Hipertensi

\begin{abstract}
Hypertension is a condition when the systolic blood pressure greater than $120 \mathrm{mmHg}$ and diastolic blood pressure over $80 \mathrm{mmHg}$. Compliance low-salt diet requires a considerable time so that family support is necessary in order to achieve compliance with a low-salt diet in patient with hypertension. This study aims to identify the relationship between family support to low-salt diet adherence in patients with hypertension in the village of Mekar Sari Tangerang Regency. This types of research is descriptive analytic research with cross sectional approach. Samples in this study a number of 42 samples. Data obtained by questionnaire respondents are then processed by Chi-square analysis test. The result showed respondents with hypertension 1 as many as 26 people $(61,9 \%)$ and Hypertension 2 as many as 16 people $(38,1 \%)$, families who provide family support is good against hypertension respondents as many as 27 people $(64,3 \%)$ while the family which does not provide family support is not good against hypertension respondents as many as 15 people $(35,7 \%)$ with Chi- square analysis test found good support $(64,3 \%)$ and adherence to low-salt diet $(54,8 \%)$ with a p-value $=0,002$. The conclusion from this research that support the families of patients hypertension associated with adherence in running a low-salt diet in patients with hypertension so it is important to improve patient adherence Hypertension in order to achieve a low-salt diet program in patients with hypertension. Expected family always provide the support and attention to the patient's recovery. The patient's recovery should be supported with the participation of health workers in improving patient understanding of the low-salt diet in patients with hypertension.
\end{abstract}

\section{Keywords: Family Support, Compliance, Patient Hypertension}




\section{PENDAHULUAN}

Hipertensi merupakan suatu keadaan ketika tekanan darah sistolik lebih dari 120 $\mathrm{mmHg}$ dan tekanan darah diastolik lebih dari $80 \mathrm{mmHg}$ dan menjadi suatu masalah serta ancaman serius yang dialami oleh beberapa negara di dunia, terutama di negara-negara berkembang salah satunya adalah Indonesia. Hipertensi yang tidak segera mendapat penanganan secara cepat akan berdampak pada munculnya penyakit degeneratif yang lain. Penyebab Hipertensi yang sulit untuk dicegah karena kebanyakan masyarakat sekitar mengkonsumsi makanan tinggi natrium.

Hipertensi sampai saat ini masih menjadi masalah utama kesehatan masyarakat dan secara global masih menjadi isu kesehatan global di Negara Indonesia. Laporan Riskesdas pada tahun

2013, mencatat pada tahun 2013 peringkat penyakit Hipertensi di Indonesia ada diposisi pertama dibawah Diabetes Mellitus, Penyakit Paru Obstruktif Kronik, Kanker, Obesitas Sentral, Penyakit Jantung Koroner dan Stroke. Namun, laporan Riskesdas pada tahun 2014 menunjukan bahwa posisi penyakit Hipertensi di wilayah provinsi Banten memiliki prevalensi Hipertensi sebesar $24,3 \%$ lebih rendah dari hasil prevalensi

Hipertensi nasional sebesar 25,8\%. Menurut laporan Dinas Kesehatan Kabupaten Tangerang (2010) Banten termasuk dalam lima provinsi dengan prevalensi Hipertensi tertinggi $(9,4 \%)$. Kabupaten Tangerang merupakan salah satu kabupaten yang berada di Provinsi Banten yang dimana dari laporan Dinas Kesehatan Kabupaten Tangerang (2012), di Kabupaten Tangerang ditemukan jumlah Hipertensi sebanyak 63095 kasus yang terbagi menjadi 19644 kasus pada pasien baru dan 43451 kasus pada pasien lama (DinKes Kabupaten Tangerang, 2009).

Dukungan keluarga tentang kepatuhan diit rendah garam merupakan suatu hal yang penting bagi pasien Hipertensi. Dukungan keluarga terkait tentang jenis dukungan keluarga, manfaat dukungan keluarga serta faktor yang mempengaruhi dukungan keluarga penting untuk diketahui agar pasien dapat memperoleh manfaat maksimal dari dukungan keluarga dan mampu meminimalkan hal yang tidak diinginkan.

Menurut data WHO (2003), pada negara berkembang tingkat kepatuhan terapi hanya $50 \%$ dan pada negara maju lebih rendah dibandingkan dengan negara berkembang. Berdasarkan Faktul (2009), terdapat empat faktor yang berhubungan dengan kepatuhan diit rendah garam yaitu usia, sistem pelayanan kesehatan, pendidikan, status sosial ekonomi, pengetahuan tentang penyakit.

$$
\text { Penelitian Priambodo }
$$
menunjukan faktor yang berhubungan dengan kepatuhan penderita Hipertensi yaitu dukungan keluarga. Sejalan dengan faktor dukungan keluarga, Musaadah (2012), menyimpulkan bahwa semakin tinggi dukungan keluarga terhadap pasien Hipetensi maka akan semakin tinggi kepatuhan pasien terhadap diit rendah garam dibandingkan dengan pasien Hipertensi yang memiliki dukungan keluarga yang rendah.

Salah satu kegunaan dari dukungan keluarga dibidang kesehatan adalah untuk dapat memberikan perawatan pada anggota keluarga yang memiliki masalah kesehatan, dengan tujuan yang paling penting agar anggota keluarga yang memiliki masalah kesehatan mampu terpenuhi kebutuhan kesehatannya secara optimal.

Pentingnya dukungan keluarga pada pasien Hipertensi tentang kepatuhan diit rendah garam dapat mempengaruhi pasien dalam terpenuhinya kebutuhan kesehatannya yang juga berpengaruh terhadap kepatuhan diit rendah garam yang sedang dijalani sebagai indikator keberhasilan pengendalian tekanan darah pada pasien Hipertensi. Sejalan dengan penelitian oleh Umami, F (2015) dengan judul hubungan pengetahuan tentang Hipertensi dan dukungan keluarga terhadap asupan natrium pasien Hipertensi rawat jalan di RSUD Kabupaten Sukoharjo sama dengan penelitian ini. Pada penelitian Umami, F (2015) didapatkan presentase $55,6 \%$ yang memiliki prosentase kepatuhan diit rendah garam dalam kategori tidak baik sehingga ada kecenderungan

JKFT, Edisi Nomor 2, Januari 2016 | 52 
bahwa semakin tinggi asupan natrium seseorang maka semakin tinggi beresiko menderita penyakit Hipertensi. Sejalan dengan penelitian oleh Umami, F (2015) ditemukan hubungan antara pengetahuan tentang Hipertensi dan dukungan keluarga terhadap asupan natrium pasien Hipertensi rawat jalan di RSUD Kabupaten Sukoharjo. Hal ini menunjukan bahwa terdapat inkonsistensi hasil penelitian terdahulu terkait hubungan antara dukungan dan kepatuhan. Disamping itu terjadinya peningkatan insiden Hipertensi dan peningkatan beban penyakit Hipertensi diseluruh dunia termasuk Indonesia menjadi alasan peneliti untuk meneliti tentang dukungan keluarga dan kepatuhan diit rendah garam dan penelitian ini bertujuan untuk mengetahui hubungan dukungan keluarga terhadap kepatuhan diit rendah garam di Kampung Mekar Sari Kabupaten Tangerang.

\section{METODE PENELITIAN}

Dalam penelitian ini peneliti menggunakan metode deskriptif analitik dengan desain cross sectional yang bertujuan untuk melihat hubungan dukungan keluarga dengan kepatuhan diit rendah garam pada pasien Hipertensi, yaitu dengan pengambilan data penelitian dalam satu waktu pada rentang waktu tertentu yang dimulai dari tanggal 1 Juni hingga 15 Juli 2016.

Sampel dalam penelitian ini berjumlah 42 orang pasien yang diambil dengan menggunakan rumus slovin dan sesuai dengan kriteria inklusi yaitu pasien Hipertensi baik tahap awal, tahap lanjutan atau pengobatan ulang maupun Hipertensi yang sudah menjalankan pengobatan kronis dan kriteria eksklusi yaitu pasien tidak suspek Hipertensi yang dilihat dari rekam medis.

Instrumen atau alat pengumpulan data yang digunakan dalam penelitian ini dikembangkan oleh peneliti dengan variabel independent "Dukungan Keluarga" yaitu berupa kuesioner dengan menggunakan skala "Likert" yang memiliki nilai reliabilitas
0,739 dan variabel dependent "Kepatuhan diit rendah garam" berupa kuesioner dengan menggunakan skala "Likert" yang memiliki nilai reliabilitas 0,78 .

\section{HASIL PENELITIAN}

Tabel 1. Distribusi Frekuensi Data Demografi Responden ( $n=42)$

\begin{tabular}{lcc}
\hline Variabel & Frekuensi & Presentase \\
\hline Umur & & \\
- 20 - 35 tahun & 21.4 & 9 \\
- 36-60 tahun & 78.6 & 33 \\
\hline Jenis Kelamin & & \\
- Laki-laki & 28,6 & 12 \\
- Perempuan & 71,4 & 30 \\
\hline TD saat pengkajian & & \\
- Hipertensi 1 & 26 & 61,9 \\
- Hipertensi 2 & 16 & 38,1 \\
\hline
\end{tabular}

Berdasarkan tabel ' 1 didapatkan hasil bahwa dari 42 responden sebagian besar responden berusia 36-60 tahun $(78,6 \%)$, jenis kelamin tertinggi adalah perempuan $(71,4 \%)$, dan tekanan darah saat pengkajian tertinggi adalah Hipertensi $(61,9 \%)$.

Tabel 2. Distribusi Frekuensi Dukungan Keluarga dan Kepatuhan Diit Rendah Garam $(\mathrm{n}=42)$

\begin{tabular}{|c|c|c|}
\hline $\begin{array}{l}\text { Dukungan Keluarga } \\
\text { dan Kepatuhan } \\
\text { Terapi }\end{array}$ & Frekuensi & Presentase \\
\hline \multirow{2}{*}{\multicolumn{3}{|c|}{$\begin{array}{l}\text { Dukungan } \\
\text { Informasional }\end{array}$}} \\
\hline & & \\
\hline$>$ Baik & 24 & 57,1 \\
\hline$>$ Tidak & 18 & 42,9 \\
\hline \multicolumn{3}{|l|}{ Dukungan Penilaian } \\
\hline$>$ Baik & 24 & 57,1 \\
\hline$>\quad$ Tidak Baik & 18 & 42,9 \\
\hline \multirow{2}{*}{\multicolumn{3}{|c|}{$\begin{array}{l}\text { Dukungan } \\
\text { Instrumental }\end{array}$}} \\
\hline & & \\
\hline$>$ Baik & 25 & 59,5 \\
\hline$>\quad$ Tidak Baik & 17 & 40,5 \\
\hline \multicolumn{3}{|l|}{ Dukungan } \\
\hline \multicolumn{3}{|l|}{ Emosional } \\
\hline$>$ Baik & 26 & 61,9 \\
\hline$>\quad$ Tidak Baik & 16 & 38,1 \\
\hline Dukungan Keluarga & & \\
\hline
\end{tabular}

JKFT, Edisi Nomor 2, Januari 2016 | 53 


\begin{tabular}{llll}
\hline$>$ & Baik & 27 & 64,3 \\
$>$ & Tidak Baik & 15 & 35,7 \\
\hline
\end{tabular}

Berdasarkan tabel 2 didapatkan hasil bahwa dari 42 responden sebagian besar responden memiliki dukungan keluarga yang terdiri dari dukungan informasional yang baik $(57,1 \%)$, dukungan penilaian yang baik $(57,1 \%)$, dukungan instrumental yang baik $(59,5 \%)$, dukungan emosional yang baik $(61,9)$, dukungan keluarga yang baik $(64,3)$ dan kepatuhan dii rendah garam dapat dikatakan sebagian besar responden patuh sejumlah 23 responden $(54,8 \%)$.

Tabel 3 Analisis Chi-Square Dukungan Informasional dan Kepatuhan $(n=42)$

\begin{tabular}{lcc}
\hline $\begin{array}{l}\text { Dukungan } \\
\text { Informasional }\end{array}$ & $\begin{array}{l}\text { Kepatuhan } \\
\text { Tidak } \\
\text { Patuh }\end{array}$ & Patuh \\
\hline Baik & 15 & 9 \\
\hline Tidak Baik & 4 & 14 \\
\hline
\end{tabular}

*p-value < $0.05 ; \mathrm{OR}=0.17$

Dari tabel 3 dengan 42 responden didapat bahwa jumlah responden berdasarkan dukungan informasional yang baik sebanyak 15 responden tidak patuh $(35,7 \%)$, 9 responden patuh $(21,4 \%)$, dan berdasarkan dukungan informasional yang tidak baik sebanyak 4 responden tidak patuh $(9,5 \%), 14$ responden patuh $(33,3 \%)$.

Hasil uji statistik Chi-Square di peroleh nilai $p$-value $=0,022$ yang berarti $p$-value < 0,05 dengan demikian Ho ditolak, artinya ada hubungan dukungan informasional dengan kepatuhan diit rendah garam pada pasien Hipertensi di Kampung Mekar Sari Kabupaten Tangerang.

Hasil analisis didapatkan pula nilai $\mathrm{OR}=0.17$ artinya dukungan informasional yang baik mempunyai peluang 0,17 kali untuk menerapkan kepatuhan diit rendah garam pada pasien Hipertensi disbanding dukungan informasional yang tidak baik.

Tabel 4 Analisis Chi-Square Dukungan Penilaian dan Kepatuhan

Dukungan Kepatuhan

\begin{tabular}{|c|c|c|}
\hline Penilaian & $\begin{array}{l}\text { Tidak } \\
\text { Patuh }\end{array}$ & Patuh \\
\hline Baik & 7 & 17 \\
\hline Tidak Baik & 12 & 6 \\
\hline
\end{tabular}

Dari tabel 4 dengan 42 responden berdasarkan dukungan penilaian yang baik sebanyak 7 responden tidak patuh (16,7\%), 17 responden patuh $(40,5 \%)$, dan berdasarkan dukungan penilaian yang tidak baik sebanyak 12 responden tidak patuh $(28,6 \%), 6$ responden patuh $(14,3 \%)$.

Hasil uji statistik Chi-Square di peroleh nilai $p$-value $=0,035$ yang berarti $p$-value < 0,05 dengan demikian Ho ditolak, artinya ada hubungan dukungan penilaian dengan kepatuhan diit rendah garam pada pasien Hipertensi di Kampung Mekar Sari Kabupaten Tangerang.

Hasil analisis didapatkan pula nilai $\mathrm{OR}$ $=4,85$ artinya dukungan penilaian yang baik mempunyai peluang 4,85 kali untuk menerapkan kepatuhan diit rendah garam pada pasien Hipertensi dibanding dukungan penilaian yang tidak baik.

Tabel 5 Analisis Chi-Square Dukungan Intrumental dan Kepatuhan

\begin{tabular}{lcc}
\hline Dukungan & \multicolumn{2}{c}{ Kepatuhan } \\
\cline { 2 - 3 } Intrumental & $\begin{array}{l}\text { Tidak } \\
\text { Patuh }\end{array}$ & Patuh \\
\hline Baik & 7 & 18 \\
\hline Tidak Baik & 12 & 5 \\
\hline \multicolumn{1}{c}{ *p-value $<0.05 ;$ OR $=6.17$} &
\end{tabular}

Dari tabel 5 dengan 42 responden didapat bahwa jumlah responden berdasarkan dukungan instrumental yang baik sebanyak 7 responden tidak patuh $(16,7 \%), 18$ responden patuh $(42,9 \%)$, dan berdasarkan dukungan instrumental yang tidak baik sebanyak 12 responden tidak patuh $(28,6 \%), 5$ responden patuh $(11,9 \%)$.

Hasil uji statistik Chi-Square di peroleh nilai $p$-value $=0,035$ yang berarti $p$-value < 0,05 dengan demikian Ho ditolak, artinya ada hubungan dukungan instrumental dengan kepatuhan diit rendah garam pada pasien Hipertensi di Kampung Mekar Sari Kabupaten Tangerang. 
Hasil analisis didapatkan pula nilai $\mathrm{OR}=$ 6,17 artinya dukungan instrumental yang baik mempunyai peluang 6,17 kali untuk menerapkan kepatuhan diit rendah garam pada pasien Hipertensi dibanding dukungan instrumental yang tidak baik.

Tabel 6 Analisis Chi-Square Dukungan Emosional dan Kepatuhan

\begin{tabular}{lcc}
\hline Dukungan & \multicolumn{2}{c}{ Kepatuhan } \\
\cline { 2 - 3 } Emosional & $\begin{array}{l}\text { Tidak } \\
\text { Patuh }\end{array}$ & Patuh \\
\hline Baik & 7 & 19 \\
\hline Tidak Baik & 12 & 4 \\
\hline *p-value $<0.05 ;$ OR $=8.14$ &
\end{tabular}

Dari tabel 6 dengan 42 responden didapat bahwa jumlah responden berdasarkan dukungan emosional yang baik sebanyak 7 responden tidak patuh $(16,7 \%), 19$ responden patuh $(45,2 \%)$, dan berdasarkan dukungan emosional yang tidak baik sebanyak 12 responden tidak patuh $(28,6 \%), 4$ responden patuh $(9,5 \%)$.

Hasil uji statistik Chi-Square di peroleh nilai $p$-value $=0,007$ yang berarti $p$-value < 0,05 dengan demikian Ho ditolak, artinya ada hubungan dukungan emosional dengan kepatuhan diit rendah garam pada pasien Hipertensi di Kampung Mekar Sari Kabupaten Tangerang.

Hasil analisis didapatkan pula nilai $\mathrm{OR}=$ 8,14 artinya dukungan emosional yang baik mempunyai peluang 8,14 kali untuk menerapkan kepatuhan diit rendah garam pada pasien Hipertensi dibanding dukungan emosional yang tidak baik.

Tabel 7 Analisis Chi-Square Dukungan Keluarga dan Kepatuhan

\begin{tabular}{lrc}
\hline Dukungan & \multicolumn{2}{c}{ Kepatuhan } \\
\cline { 2 - 3 } Keluarga & $\begin{array}{l}\text { Tidak } \\
\text { Patuh }\end{array}$ & Patuh \\
\hline Baik & 7 & 20 \\
\hline Tidak Baik & 12 & 3 \\
\hline
\end{tabular}

$*$ p-value $<0.05 ;$ OR $=11.43$
Dari tabel 7 dengan 42 responden didapat bahwa jumlah responden berdasarkan dukungan keluarga yang baik sebanyak 7 responden tidak patuh $(16,7 \%), 20$ responden patuh $(47,6 \%)$, dan berdasarkan dukungan keluarga yang tidak baik sebanyak 12 responden tidak patuh (28,6\%), 3 responden patuh $(7,1 \%)$.

Hasil uji statistik Chi-Square di peroleh nilai $p$-value $=0,002$ yang berarti $p$-value < 0,05 dengan demikian Ho ditolak, artinya ada hubungan dukungan keluarga dengan kepatuhan diit rendah garam pada pasien Hipertensi di Kampung Mekar Sari Kabupaten Tangerang.

Hasil analisis didapatkan pula nilai $\mathrm{OR}=11,43$ artinya dukungan keluarga yang baik mempunyai peluang 11,43 kali untuk menerapkan kepatuhan diit rendah garam pada pasien Hipertensi dibanding dukungan keluarga yang tidak baik.

\section{PEMBAHASAN}

Dalam penelitian ini ditemukan bahwa terdapat hubungan yang signifikan antara dukungan keluarga dengan kepatuhan. Hasil penelitian ini sesuai dengan penelitian Ningrum, S dan Hendarsih, S (2012), yang dimana ditemukan hubungan dukungan keluarga dengan perilaku makan pada pasien Hipertensi di Wilayah Kerja Puskesmas Minggir Sleman Yogyakarta. Hasil penelitian ini juga sesuai dengan penelitian Rosiana, A (2015), dimana terdapat hubungan yang signifikan antara pengaruh pendampingan perilaku diet Hipertensi terhadap kepatuhan diet pada pasien Hipertensi di Kampung Sanggrahan dan terdapat kesamaan dari karakteristik diit yang tidak seimbang dimana rata-rata responden sering mengkonsumsi makanan bernatrium tinggi.

Pasien Hipertensi dengan dukungan keluarga yang baik dalam menerapkan diit yang seimbang memiliki kemungkinan patuh terhadap kepatuhan diit rendah garam sebanyak 11,43 kali dibandingkan dengan pasien Hipertensi yang memiliki dukungan keluarga yang tidak baik. Hal ini ditunjukan dengan mayoritas pasien Hipertensi memiliki dukungan keluarga yang baik (64,3\%). 
Sehingga penerapan dukungan keluarga yang baik mengenai diit yang seimbang merupakan hal penting dalam kepatuhan.

$$
\text { Menurut Faktul (2009) dukungan }
$$

keluarga merupakan suatu respon sikap, tindakan dan penerimaan keluarga terhadap anggota keluarga yang menderita sakit. Anggota keluarga memandang bahwa orang yang bersifat mendukung adalah orang yang selalu siap memberikan pertolongan dan bantuan jika diperlukan.

Dukungan keluarga merupakan faktor penting terkait kepatuhan, menurut Friedman (2002) dukungan keluarga dapat dipengaruhi oleh tingkat pendapatan, dan tingkat pendidikan. Pada penelitian ini ditemukan bahwa sebagian besar pasien Hipertensi termasuk kedalam pekerjaan sebagai buruh $(58,6 \%)$ dan pendidikan rendah $(42,2 \%)$, dan hal ini dapat menunjukan keterkaitan terhadap kemampuan seseorang untuk memperoleh dukungan dari anggota keluarga.

Kepatuhan terhadap aturan diit mengacu pada definisi yang dijelaskan sebagai suatu perilaku pasien untuk mengikuti tindakan pengobatan dan menjaga pola hidup sehat. Menurut (Stanley, 2007) dalam penerapan diit, seseorang dikatakan tidak patuh apabila orang tersebut melalaikan kewajibanya dalam membatasi asupan natrium, sehingga terhalangnya kesembuhan dan dikatakan patuh bila mau membatasi asupan natrium yang telah ditentukan sesuai dengan tingkatan tekanan darah yang dialami serta mau melaksanakan apa yang dianjurkan oleh petugas.

Lamanya proses pengobatan dapat mengakibatkan penderita jenuh sehingga beresiko mengalami putus asa yang dapat mengakibatkan pengobatan tidak tuntas dan sulit disembuhkan. Dukungan keluarga mengenai penyakit Hipertensi, kepatuhan diit rendah garam yang diperlukan berhubungan dengan kepatuhan pasien Hipertensi untuk menerapkan diit yang seimbang. Hal ini sejalan dengan penelitian Musaadah (2012), dalam penelitianya didapatkan hasil bahwa terdapat hubungan yang signifikan antara dukungan keluarga dengan kepatuhan diit rendah garam.

\section{KESIMPULAN}

Dari hasil penelitian di Kampung Mekar Sari Kabupaten yang dilakukan pada tanggal 1 Juni hingga 15 Juli diperoleh distribusi dukungan informasional, dukungan penilaian, dukungan instrumental, dukungan emosional, dukungan keluarga bahwa dari

42 responden didominasi oleh responden dengan dukungan informasional baik sebanyak 24 responden $(57,1 \%)$, dukungan penilaian baik sebanyak 24 responden $(57,1 \%)$, dukungan instrumental baik sebanyak 25 responden (59,5\%), dukungan emosional baik sebanyak 26 responden $(61,9 \%)$, dukungan keluarga baik sebanyak 27 responden $(64,3 \%)$ sedangkan kepatuhan diit rendah garam pada pasien Hipertensi di dominasi oleh responden yang patuh terhadap diit rendah garam sebanyak 23 responden $(54,8 \%)$.

Hasil analisis penelitian memperlihatkan hubungan dukungan informasional dengan kepatuhan diit rendah garam yaitu didapatkan nilai $p$-value $<0,05$ menandakan bahwa Ho ditolak dan dapat diartikan bahwa terdapat hubungan dukungan informasional dengan kepatuhan diit rendah garam di Kampung Mekar Sari Kabupaten Tangerang. Disamping itu didapatkan nilai OR sebesar

0,17 artinya dukungan informasional yang baik mempunyai peluang 0,17 kali untuk menerapkan kepatuhan diit rendah garam pada pasien Hipertensi dibanding dukungan informasional yang tidak baik.

Hasil analisis penelitian memperlihatkan hubungan dukungan penilaian dengan kepatuhan diit rendah garam yaitu didapatkan nilai $p$-value <

0,05 menandakan bahwa Ho ditolak dan dapat diartikan bahwa terdapat hubungan dukungan penilaian dengan kepatuhan diit rendah garam di Kampung Mekar Sari Kabupaten Tangerang. Disamping itu didapatkan nilai OR sebesar 4,85 artinya dukungan penilaian yang baik mempunyai peluang 4,85 kali untuk menerapkan kepatuhan diit rendah garam pada pasien Hipertensi dibanding dukungan penilaian yang tidak baik.

Hasil analisis penelitian memperlihatkan hubungan dukungan instrumental dengan 
kepatuhan diit rendah garam yaitu didapatkan nilai $p$-value <

0,05 menandakan bahwa Ho ditolak dan dapat diartikan bahwa terdapat hubungan dukungan instrumental dengan kepatuhan diit rendah garam di Kampung Mekar Sari Kabupaten Tangerang. Disamping itu didapatkan nilai OR sebesar 6,17 artinya dukungan instrumental yang baik mempunyai peluang 6,17 kali untuk menerapkan kepatuhan diit rendah garam pada pasien Hipertensi dibanding dukungan instrumental yang tidak baik.

Hasil analisis penelitian memperlihatkan hubungan dukungan emosional dengan kepatuhan diit rendah garam yaitu didapatkan nilai $p$-value <

0,05 menandakan bahwa Ho ditolak dan dapat diartikan bahwa terdapat hubungan dukungan emosional dengan kepatuhan diit rendah garam di Kampung Mekar Sari Kabupaten Tangerang. Disamping itu didapatkan nilai OR sebesar 8,14 artinya dukungan emosional yang baik mempunyai peluang 8,14 kali untuk menerapkan kepatuhan diit rendah garam pada pasien Hipertensi dibanding dukungan emosional yang tidak baik.

Hasil analisis penelitian memperlihatkan hubungan dukungan keluarga dengan kepatuhan diit rendah garam yaitu didapatkan nilai $p$ value <

0,05 menandakan bahwa Ho ditolak dan dapat diartikan bahwa terdapat hubungan dukungan keluarga dengan kepatuhan diit rendah garam di Kampung Mekar Sari Kabupaten Tangerang. Disamping itu didapatkan nilai OR sebesar 11,43 artinya dukungan keluarga yang baik mempunyai peluang 11,43 kali untuk menerapkan kepatuhan diit rendah garam pada pasien Hipertensi dibanding dukungan keluarga yang tidak baik.

\section{SARAN}

Hasil penelitian ini diharapkan dapat berkontribusi terhadap kepatuhan dengan peningkatan pelayanan terhadap pasien Hipertensi terutama dalam pendidikan kesehatan mengenai diit yang seimbang dan pembatasan mengkonsumsi natrium. Hasil penelitian ini menunjukan adanya hubungan antara dukungan keluarga dengan kepatuhan sehingga keterbatasan pada penelitian ini yaitu jumlah sampel yang dimiliki diharapkan bagi peneliti selanjutnya untuk menggunakan sampel dengan jumlah yang lebih besar.

\section{DAFTAR REFERENSI}

Agrina. (2011). Kepatuhan Pasien Hipertensi dalam

Pemenuhann Diet Hipertensi, Jurnal Keperawatan, Vol. 6 No. 1. Jogyakarta: Nuha Medika. Diakses pada tanggal 12 Januari 2016.

Almatsier, (2006). Penuntun Diit Edisi

Baru. Jakarta: PT. Gramedia Pustaka Utama.

Anggara \& Prayitno, N. (2012). Faktor- Faktor Yang Berhubungan Dengan Tekanan Darah Di Puskesmas Telaga Murni Cikarang Barat. Diakses pada tanggal 12 Mei 2016.

Austriani. (2008). Risiko Perilaku Perawatan Diri Pasien

Hipertensi Terhadap Kejadian

Penyakit Jantung Koroner

Pada Pasien Hipertensi.

Diakses pada tanggal 12 Januari 2016.

Ayuningtyas, E dan Ruhyana. (2012). Peran Keluarga Dalam Pemenuhan Kebutuhan Diet Hipertensi Di Wilayah Kerja Puskesmas Sleman. Yogyakarta: Stikes Aisyiyah. Diakses pada tanggal 12 Januari

2016.

Balitbang Kemenkes RI. (2013). Riset Kesehatan Dasar; RISKESDAS. Jakarta: Balitbang Kemenkes RI.

Dalimartha. (2008). Care Your Self Hipertensi. Jakarta: Penebar Plus.

Dharma, K. (2013). Metodologi Penelitian Keperawatan. Jakarta: Trans Info Media. 
Departemen Kesehatan RI. (2012). Angka kejadian hipertensi di Indonesia. Jakarta: Direktorat Kesehatan Keluarga.

Diana, T. (2013). Hubungan Dukungan Keluarga Dengan Motivasi Klien Diabetes Melitus Untuk Melakukan Latihan Fisik Di Dinas Kesehatan Dan
Kesejahteraan Sosial Kabupaten Klaten. Yogyakarta: Stikes Aisyiyah. Diakses pada tanggal 4 Agustus 2016.

DinKes Kab Tangerang. (2009). Penelitian dan Pengembangan Pemberdayaan Posyandu di Kab Tangerang. Tangerang: DinKes $\mathrm{Kab}$ Tangerang 